\title{
The Role of Tissue Microenvironment in Breast Cancer Development and Importance of its Behavioral Profiling for Individually Tailored Therapy
}

\section{Pavol Zubor*}

Jessenius medical faculty, Department of Obstetrics and Gynecology, Comenius University in Martin, Slovak republic

Invasive breast cancer is the endpoint of complicated evolutionary process starting in TDLU of mammary gland. It is the network of multiple-step mechanism including cell proliferation, differentiation, atypical intracellular expression and signaling leading to the misbalance between mammary epithelial cells and breast tissue microenvironment. The disruption of epithelial-stromal equilibrium can lead to the epithelial carcinogenesis, progressive stromal invasion and metastatic spread in the final stages. Although we know some of the histopathologic features in these mechanisms, the molecular profile of these events is still not adequately responded, and remains the scope for future research.

The current knowledge is pointing on dual functioning activity of breast tissue microenvironment on breast carcinogenesis. Once it can stimulate it, other time has abilities to block malign transformation, as well as eliminate the cells with malign phenotype [1]. The first reports describing the active role of tissue microenvironment signaling activity on breast carcinogenesis and character of malign cell clones, e.g. the form of tumor grade are more than 30 years old [2]. The technologic advance in the molecular and tissue cell biology, mainly through geneexpression profiling approaches, allowed us over the last decade to detect and actively describe the role of myoepithelial cells, fibroblasts, adipocytes, immune system cells, growth and hormone factors, extra-cellular matrix, and epithelial-mesenchymal transition in the complicated process of progressive epithelial cell transformation into the pre-invasive and invasive forms of breast lesions [3,4]. These breast tissue micro-environmental "structures" are currently commonly described by mammary pathologists when reporting findings from breast lesion biopsies. Moreover, these findings show the cancer phenotype specific linkages in their morphologic variability or achievement of invasive status. Typical example of such biologic variability in microenvironment modified and controlled carcinogenesis is the dual form (barrier escape / failure) of DCIS transition to invasive breast carcinoma. The barrier escape is associated with the topic disruption of myoepithelial cells line and basement membrane tumor cells, allowing them to migrate and spread into surrounding stroma. However, in the case of barrier failure the disruption of myoepithelial cells line and basement membrane occur generally in their whole extent, followed by massive lymphocyte infiltration and accumulation of myofibroblasts [5]. Apart of this, data in the literature are proving the direct impact of microenvironment signaling on cancer biologic features and its latter clinical behavior. Finally, the astonishing story describing the crucial role of breast microenvironment in evolution of mammary carcinomas is the development and descriptionof "premetastatic niche concept". This is the concept that describes the active signaling role of microenvironment on progenitor cells, stem cells or aggressive cancer clonal cells in the role of their migration, malign transformation and location the sites of future metastases [6,7] together with the active host cells participation coming mainly from host bone-marrow cell migration able population [8]. In this special issue, the active role of microenvironment components is discussed at the level of activity of cytotoxic suppressor cells, neoangiogenic, immunosuppressive factors [9] and role of adipocytes [10] in the mammary tissue microenvironment in the process of breast tumorogenesis and selection of targeted therapy in patients resistant to endocrine treatment.

The progress in health directed technology is moreover associated with the advances in molecular profiling of breast carcinomas and subsequent growth of personalized medicine. It is well accepted, that the breast carcinoma is one of the most heterogeneous types of human cancer that integrates variable spectra of epithelial and stromal components with immense functional impact on affected subject. Based on some of them (e.g. ER, PgR, Her-2, MIB-1, Ki67, cytokeratines, etc...) we can recognize two most frequent (ductal / lobular) and more than 30 other histological subtypes of breast carcinomas [11]. This large phenotype variability is mainly the result of different carcinogenesis mechanisms and microenvironmental signaling. Supporting data from large follow-up studies indicate that even basic clinical-pathologic parameters of both most frequent types of breast cancer (ductal / lobular) can be similar, e.g. tumor size, grade or stage; the overall survival, disease-free survival rate, loco-regional recurrence rate or distant metastases free interval is markedly different $[12,13]$. This heterogeneity was confirmed by the epidemiologic, age, race and ethnic directed studies, and molecular or pathology focused studies bringing new insights into the features resembling hormonal expression, proliferative, apoptotic, migration, adhesion and/or metastatic activity, as well as histopatological evidence of e.g. (neo)adjuvant therapy. All these new findings gradually changed the routine concept of breast cancer patient selection into specific groups (e.g. low/high grade, ER positive/negative, Her-2 positive/negative, chemotherapy response sensitive/negative subject). Furthermore, not only progress in diagnostic approaches in pathology ( $\mathrm{H} \& \mathrm{E} \rightarrow \mathrm{IHC}$ $\rightarrow$ CISH/FISH), but also progress in breast cancer molecular biology (cDNA, miRNA expression, clonal heterogeneity) and clinical followup studies (survival $\rightarrow$ recurrence $\rightarrow$ race, age phenotype, stage and therapeutic protocol used specificities in disease behavior) allowed the transition from many years used routine oncologic management,

*Corresponding author: Pavol Zubor, MD, PhD, Jessenius medical faculty Comenius University in Martin, Department of Obstetrics and Gynecology, Kollarova 2, 036 01, Martin, Slovak republic, Tel: 00421434203 242; Fax: 004214341341 85; E-mail: zubor@jfmed.uniba.sk

Received December 20, 2011; Accepted December 22, 2011; Published December 22, 2011

Citation: Zubor P (2011) The Role of Tissue Microenvironment in Breast Cance Development and Importance of its Behavioral Profiling for Individually Tailored Therapy. J Cancer Sci Ther S2. doi:10.4172/1948-5956.S2-e001

Copyright: (c) 2011 Zubor P. This is an open-access article distributed under the terms of the Creative Commons Attribution License, which permits unrestricted use, distribution, and reproduction in any medium, provided the original author and source are credited. 
including surgery and adjuvant therapy to individually tailored chemo- and/or hormonal therapy. The oncologic practice proved that stratification of the patients with breast cancer only by common prognostic and predictive parameters into risk groups and subsequent treatment protocols is not effective for everybody, and has limitations in the prediction of future biologic behavior of the disease $[14,15]$. This experience has started a huge rise in genomic and molecular analyses of breast cancer and/or histologically normal tumor surrounding tissue focusing on the improvements in diagnostic and prognostic specificity, and prediction of adjuvant therapeutic sensitivity. Thus, we are being spectators of revolutionary transition from morphologic phenotype description to molecular taxonomy of breast carcinomas [16]. This taxonomy based on specific multigene-expression features of each breast cancer types reflects their biologic uniqueness. It is evident that this molecular approach can not only enrich, but has a potential to substitute traditional models of prognostic and predictive parameters (PPP) assessment in selection of patients for adjuvant management [17], that can be individually different for each patient [18-20].

The use of gene signatures in adjuvant management in women with breast cancer has brought new insights into the selection of therapeutic approaches and cost-benefit analyses. It is evident in oncology practice that response to any treatment is individually specific in the expression of side effects, relapses or remissions of the disease, though patients are stratified into the same risk group with similar disease features and stage, (Figure 1).

Therefore, adequate surgical interventions and the correct use of tests and tools, which can determine the optimal therapy for the patients, have to become the indispensable approach to be made by every physician when counseling their oncologic patients in the aim to achieve the best clinical outcome, and alleviate symptoms related to treatments strategies. This issue is focused on some of this aspects, e.g. age related comorbidity, oncological safety of surgery and specific determinants for improvement in individual therapy for hormonal receptor positive metastatic breast cancer [21-24]. I hope the readers will find this aspects of breast cancer management useful and will transfer and access new data for patient information.
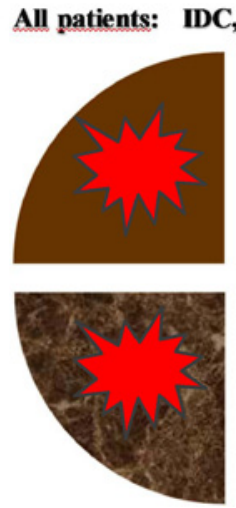

Figure 1: Model of adjuvant chemotherapy effectiveness in therapeutic approaches with similar chemotherapy protocols used based only on common prognostic-predictive parameters without assessment of individual gene profile of carcinomas. (All patients belong to the same risk group of disease, have similar histologic features, stage of the disease and adjuvant chemotherapy protocol used. However, the true benefit - Responders without side effect accounts only for $25 \%$. Fifty $\%$ of patients does not benefit from chemotherapy selected on the results from common PPP).
Altogether, I believe that there is a good trend and situation in the healthcare system to support our need for new insights into the process of breast carcinogenesis, role of tumor and surrounding tissue microenvironment signaling activity, phenotype determination and molecular profiling of breast carcinomas in the great aim to bring down all barriers between basic, translational research and the clinical application for the benefit in breast cancer patients worldwide.

\section{Acknowledgement}

I declare no conflict of interest. The work was supported by grant VEGA 1/0069/09 and project ITMS: 26220120036 Centre of excellence for perinatology research (CEPV II) co-financed from EU sources.

\section{References}

1. McCave EJ, Cass CA, Burg KJ, Booth BW (2010) The normal microenvironment directs mammary gland development. J Mammary Gland Biol Neoplasia 15 291-299.

2. DeCosse JJ, Gossens CL, Kuzma JF, Unsworth BR (1973) Breast cancer: induction of differentiation by embryonic tissue. Science 181: 1057-1058.

3. Schedin P, Borges V (2009) Breaking down barriers: the importance of the stromal microenvironment in acquiring invasiveness in young women's breast cancer. Breast Cancer Res 11: 102

4. Cichon MA, Degnim AC, Visscher DW, Radisky DC (2010) Microenvironmenta influences that drive progression from benign breast disease to invasive breas cancer. J Mammary Gland Biol Neoplasia 15: 389-397.

5. Polyak K, Kalluri R (2010) The role of the microenvironment in mammary gland development and cancer. Cold Spring Harb Perspect Biol 2: a003244.

6. Kaplan RN, Rafii S, Lyden D (2006) Preparing the "soil": the premetastatic niche. Cancer Res 66: 11089-11093.

7. Psaila B, Lyden D (2009) The metastatic niche: adapting the foreign soil. Nat Rev Cancer 9: 285-293.

8. Hattori K, Ishihara M, Heissig B (2008) Bone marrow-derived cells contribute to niche formation in cancer progression. Clin Calcium 18: 480-487.

9. Zavadova E, Vocka M, Konopasek B, Fucikova T, Petruzelka L (2011) Breas cancer patients resistant to endocrine therapy show decreased number of cytotoxic suppressor cells and enhanced production of neoangiogenetic and immunosupressive factors. J Cancer Sci Ther S2: 005.

10. Jones LP, Buelto D, Tago E, Owusu-Boaitey KE (2011) Abnormal mammary adipose tissue environment of Brca1 mutant mice show a persistent deposition of highly vascularized multilocular adipocytes. J Cancer Sci Ther S2: 004.

11. Fabbri A, Carcangiu ML, Carbone A (2008) Histological Classification of Breast Cancer. Breast Cancer 1: 3-14.

12. Silverstein MJ, Lewinsky BS, Waisman JR, Gierson ED, Colburn WJ, et al. (1994) Infiltrating lobular carcinoma. Is it different from infiltrating duct carcinoma? Cancer 73: 1673-1677

13. Mann RM, Veltman J, Huisman H, Boetes C (2011) Comparison of enhancement characteristics between invasive lobular carcinoma and invasive ductal carcinoma. J Magn Reson Imaging 34: 293-300.

14. Rakha EA, Ellis IO (2011) Modern classification of breast cancer: should we stick with morphology or convert to molecular profile characteristics. Adv Anat Pathol 18: 255-267.

15. Ross JS (2009) Multigene classifiers, prognostic factors, and predictors of breast cancer clinical outcome. Adv Anat Pathol 16: 204-215.

16. Schnitt SJ (2010) Classification and prognosis of invasive breast cancer: from morphology to molecular taxonomy. Mod Pathol 23: S60-S64.

17. Goldstein LJ, Gray R, Badve S, Childs BH, Yoshizawa C, et al. (2008) Prognostic utility of the 21-gene assay in hormone receptor-positive operable breast cancer compared with classical clinicopathologic features. J Clin Onco 26: 4063-4071.

18. Jönsson G, Staaf J, Vallon-Christersson J, Ringnér M, Holm K, et al. (2010) 
Citation: Zubor P (2011) The Role of Tissue Microenvironment in Breast Cancer Development and Importance of its Behavioral Profiling for Individually Tailored Therapy. J Cancer Sci Ther S2. doi:10.4172/1948-5956.S2-e001

Page 3 of 3

Genomic subtypes of breast cancer identified by array-comparative genomic hybridization display distinct molecular and clinical characteristics. Breast Cancer Res 12: R42.

19. Weigelt B, Geyer FC, Reis-Filho JS (2010) Histological types of breast cancer: how special are they? Mol Oncol 4: 192-208.

20. Leong AS, Zhuang Z (2011) The changing role of pathology in breast cancer diagnosis and treatment. Pathobiology 78: 99-114.

21. Janelsins MC, Mustian KM, Peppone LJ, Sprod LK, Shayne M (2011) Interventions to alleviate symptoms related to breast cancer treatments and areas of needed research. J Cancer Sci Ther S2: 001.
22. Ruiz M, Cefalu CH, Reske T (2011) Breast cancer in senior patients: Role of comprehensive geriatrics assessment and comorbidities. J Cancer Sci Ther S2: 002.

23. da silva AV, Destro C, de Figueiredo JCB, Dias EP, Torres W (2011) A comparison between the oncological safety of oncoplastic and conventional conservative breast surgery. J Cancer Sci Ther S2-006.

24. Copur MS, Obermiller AM, Ramaekers R, Bolton M, Luebbe B (2011) Fulvestrant in combination with letrozole in second line or more estrogen receptor positive metastatic breast cancer; efficacy and predictive factors of response. J Cancer Sci Ther S2: 003. 